Article

\title{
Design and Implementation of Solar OLED Lighting Driver Circuit with Frequency Modulation Control
}

\author{
Zhong-Rong Lin * and Huang-Jen Chiu
}

Department of Electronic and Computer Engineering, National Taiwan University of Science and Technology, Taipei 10607, Taiwan; hjchiu@mail.ntust.edu.tw

* Correspondence: D10402202@mail.ntust.edu.tw; Tel.: +886-933654847

Received: 30 September 2020; Accepted: 23 October 2020; Published: 27 October 2020

\begin{abstract}
This paper proposes a single-stage single-ended primary inductor converter (SEPIC) converter circuit, which is applied to the organic light-emitting diodes (OLED) driver circuit. The circuit proposed in this paper replaces the output Schottky diode from the original SEPIC with a power switch. Deadtime is added to prevent the on-state overlapping of two switches with zero voltage switching (ZVS), and the circuit operates in triangular current mode. The digital control methods are maximum power point tracking and frequency modulation using a battery to supply the converter and illuminate the OLED at night. Finally, a prototype is implemented to show the feasibility under the DC input voltage range of $10-40 \mathrm{~V}$. The DC output is $12 \mathrm{~V} / 1 \mathrm{~A} / 12 \mathrm{~W}$, and the conversion efficiency is up to $96.3 \%$.
\end{abstract}

Keywords: SEPIC converter; zero voltage switching; triangular current mode; frequency modulation; maximum power point tracking

\section{Introduction}

Light-emitting diode (LED) is currently used in saturation, i.e., in lighting and screen backlighting. Organic light-emitting diodes (OLEDs) were invented at about the same time as LEDs. The organic materials used to create OLEDs are expensive to manufacture, and OLED's efficiency and yield are very low. LEDs are inefficient with high costs but are widely used. In recent years, progress in the cost and production of OLED materials has greatly improved efficiency and yield, and engineers are designing OLED power supply drivers to reduce their development. Then, OLEDs can be used with LED power supplies. The design architecture coexists, and the color rendering and color saturation of OLED are higher than those of LED. The OLED color wavelength is not affected by blue light, as shown in Figure 1 [1] and is more suitable for lighting, especially indoor lighting. Figure 2 shows the OLED structure; the upper and lower layers are the substrate, anode, hole injection layer (HIL), hole transport layer (HTL), emissive layer (EML), electron transport layer (ETL), electron injection layer (EIL), and cathode. The upper and lower substrates of OLED in the manufacturing process can be transparent materials, such as glass and plastic; thus, OLED can become a large flat surface, and the size can be determined freely. It appears as a surface light source that is thin and light, and the substrate material can be selected. The characteristics of flexibility and forgiveness are ideal for future needs $[2,3]$. 


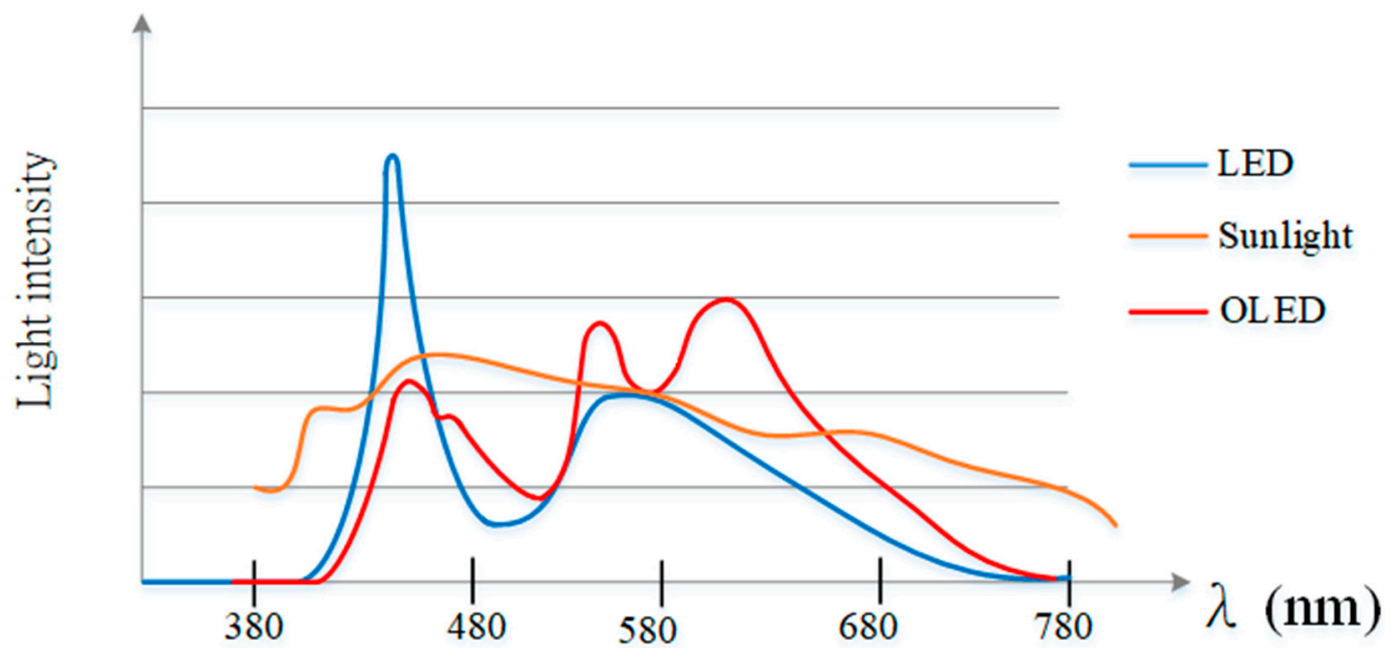

Figure 1. Light-emitting diode (LED), organic light-emitting diodes (OLED), and sunlight of waveform.

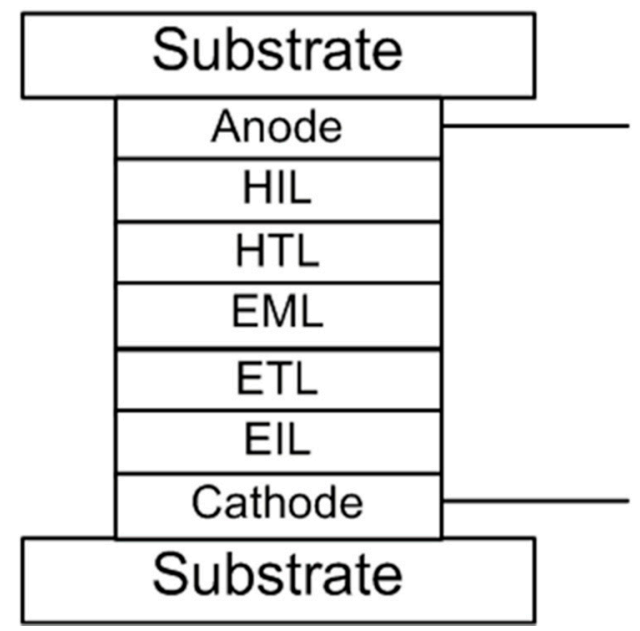

Figure 2. OLED Structure.

At present, the power supply of OLED is generally driven by commercial power through AC-DC and DC-DC converters. The DC-driven OLED that comes out makes the OLED bright [3-5]. OLED is an emerging light source in the lighting field. It can be produced according to different needs [6]. It is one piece and does not occupy space. It can be miniaturized according to the design of the driving circuit [7-9]. The power supply is provided by solar energy, which is combined with an energy storage battery that provides energy during the day and night.

The solar energy supplies a range of voltages, and maximum power point tracking (MPPT) is also added to enable the load and battery to obtain the maximum power when the weather changes. The solar panel is connected to a SEPIC circuit [10-12] as a conversion circuit, and the output is connected to the OLED and the battery. The overall operation mode is divided into four methods, as follows: When the solar panel and battery energy are lower than a voltage level, the OLED cannot be bright; when the solar panel is lower than a voltage level, the battery is fully charged at this time, and the energy of the OLED is supplied by the battery; when the solar panel has a certain voltage, OLED energy is provided by solar panels; when the solar panel and battery have a certain voltage, the OLED energy is directly supplied by solar energy. This paper proposes the block diagram of the circuit system, shown in Figure 3. 


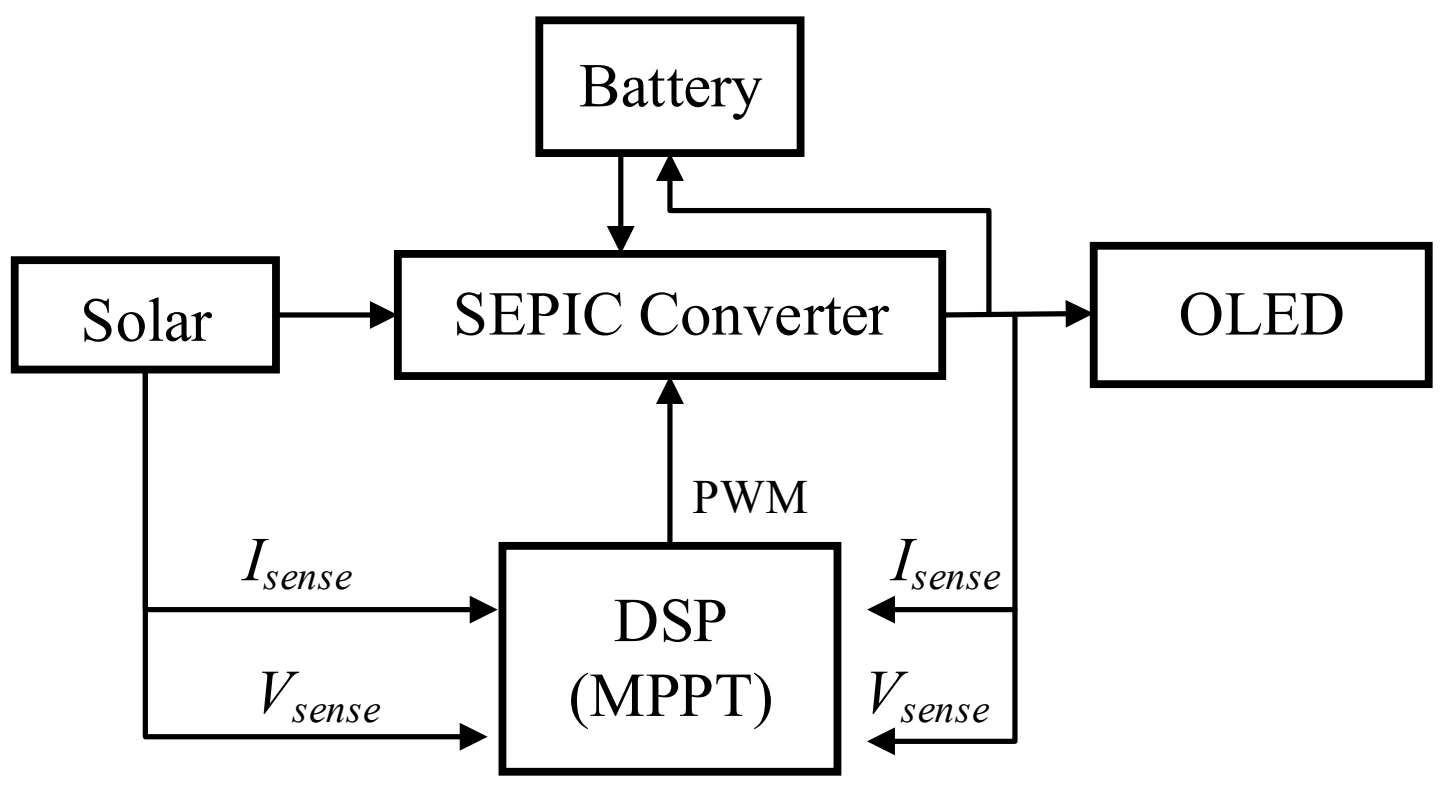

Figure 3. System block diagram.

\section{Original Single-Ended Primary Inductor Converter (SEPIC) Converter}

For a SEPIC circuit, the output voltage can be greater than, less than, or equal, to its input voltage. SEPIC is essentially a boost converter, followed by a reverse buck-boost converter. Thus, it is similar to the traditional buck-boost converter but has the advantage of a non-inverting output, that is, the output has the same voltage polarity as the input.

As shown in Figure 4, the basic circuit architecture of SEPIC is composed of the following: two inductors, namely, $L_{1}$ and $L_{2}$; switch $S_{1}$ as MOSFET; Schottky diode $D_{1}$; AC coupling capacitor $C_{1}$; and output capacitor $C_{0}$. In steady-state continuous conduction operation mode analysis, the two actions are as follows: when the switch is conducting and when it is not conducting.

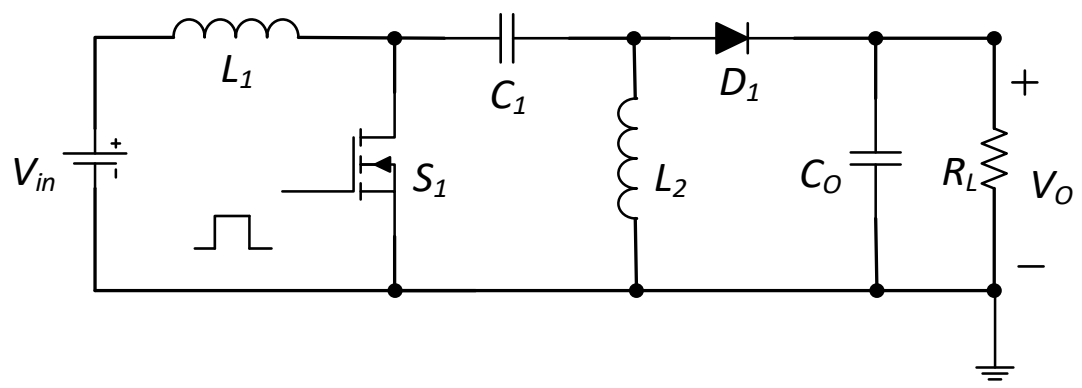

Figure 4. Original single-ended primary inductor converter (SEPIC) converter circuit.

Figure 5 shows the original SEPIC converter circuit operation in continuous conduction mode (CCM). Mode 1, the current direction color is red, when switch $S_{1}$ is turned on, two loops are formed, namely, $I_{\mathrm{L} 1}$ flowing through $L_{1}$, and $I_{\mathrm{L} 2}$ flowing through $C_{1}$ and $S_{1}$. At this time, $D_{1}$ is not reversed, and the output capacitor $C_{0}$ discharges the load $R_{\mathrm{L}}$; Mode 2 , the current direction color is blue, when the switch $S_{1}$ is not turned on, two loops are formed, which are as follows: the inductor $L_{1}$ flowing through the inductor $L_{1}$, capacitor $C_{1}$, diode $D_{1}$, the output capacitor $C_{0}$, and the load $R_{\mathrm{L}}$; and the inductor $L_{2}$ flowing through the two pole bodies $D_{1}$, the output capacitor $C_{0}$, and the load $R_{\mathrm{L}}$. At this time, $D_{1}$ is forward biased. 


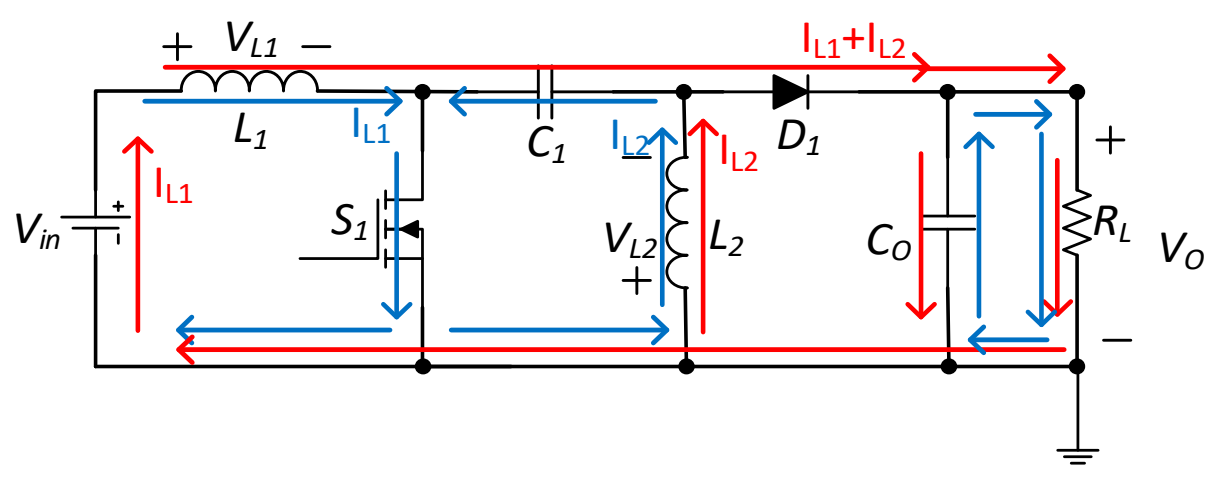

Figure 5. Operation in continuous conduction mode (CCM).

The SEPIC converter action waveform is shown in Figure 6.

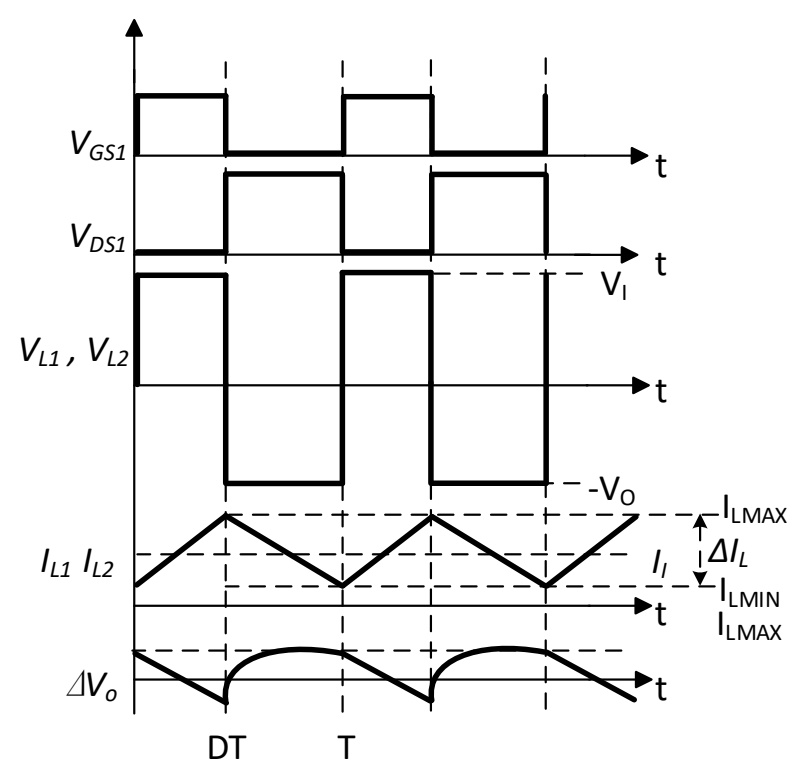

Figure 6. SEPIC action waveform.

\section{TCM SEPIC Converter with Zero Voltage Switching}

The original SEPIC converter in the continuous conduction mode of the main power switch is hard switching (hard switching). However, when the power switch is operated in the hard-cut state, the efficiency of the overall circuit decreases, the loss increases, the power density decreases, and the loss increases the switching frequency and input voltage to limit the maximum frequency operation. To avoid this situation, operating the power switch at zero voltage switching is necessary. When the collector source voltage $\left(V_{D S}\right)$ drops to zero, before the switch is turned on, the gate source is set up to establish the voltage.

As shown in Figure 7, the output Schottky diode is changed to a power switch. The switch control method lets the main power switch turn on first, and then have a short dead time. The power switch near the output terminal is turned on. The circuit operation is shown in Figure 8, the inductor current drops to below zero, which is the negative level at which the main power switch is not conducting. Then, the $V_{D S}$ of the main power switch first drops to zero level. The main power switch is turned on; thus, the main power switch operates at zero voltage switching. The operation waveform is shown in Figure 9. 


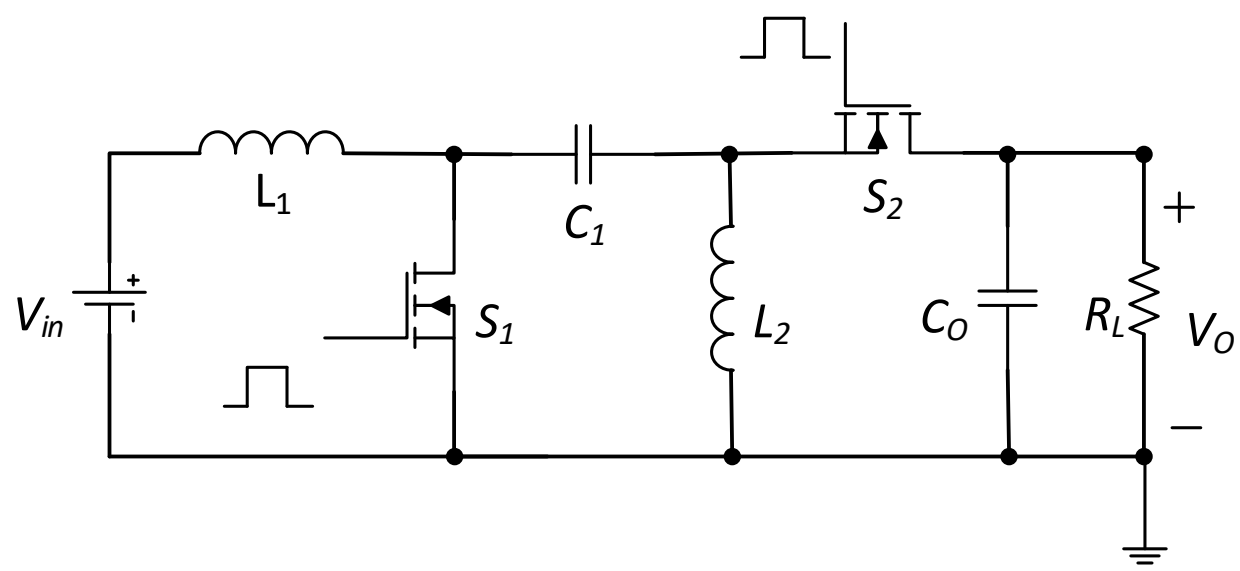

Figure 7. Schottky diode change to power switch.

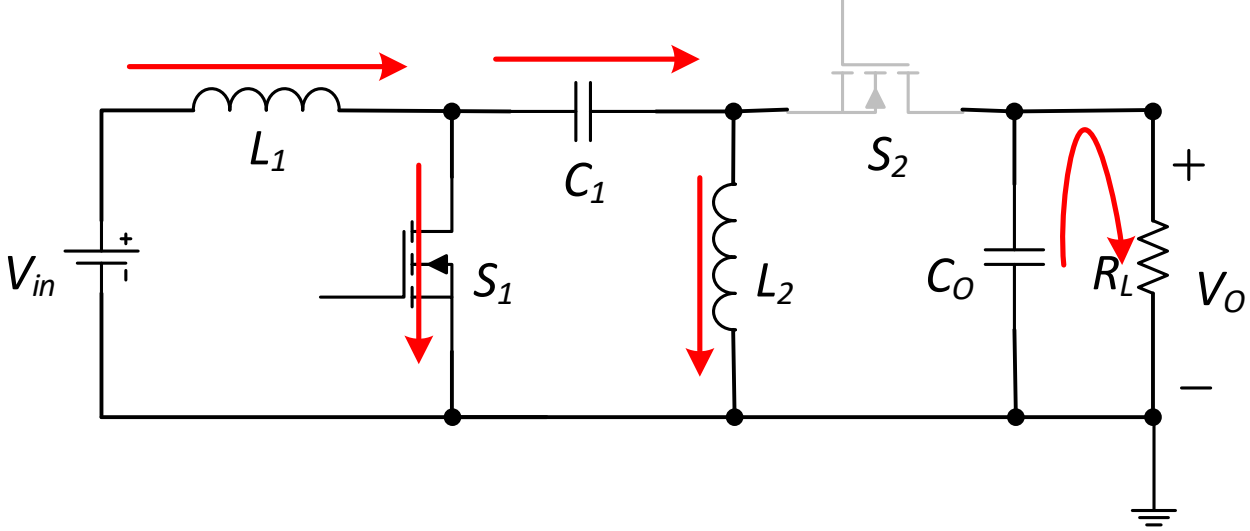

(a)

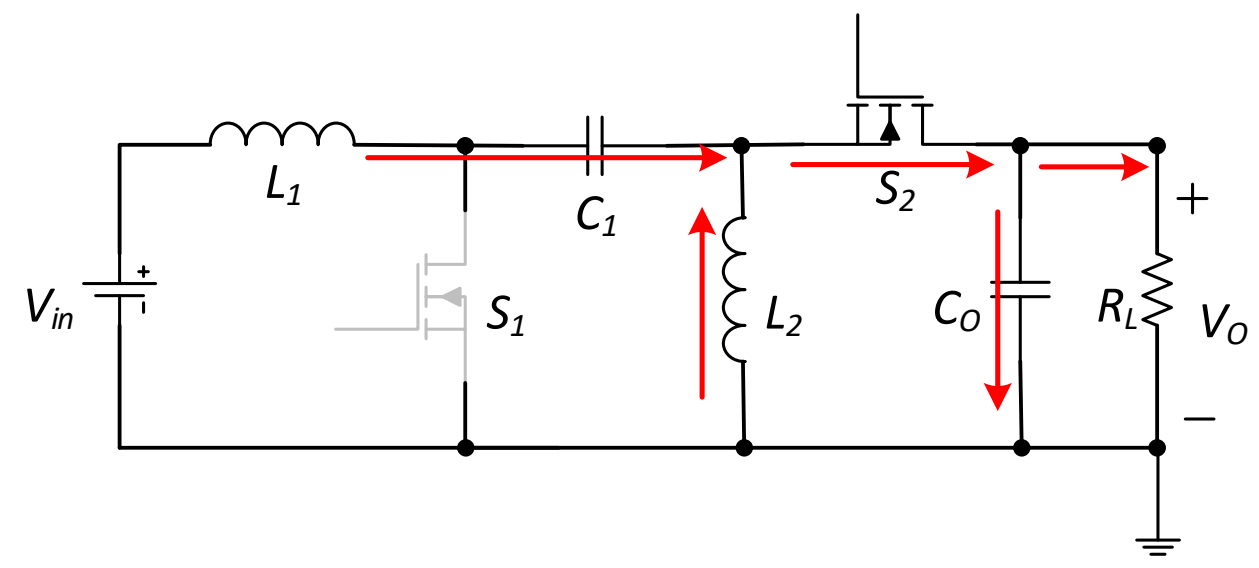

(b)

Figure 8. Circuit operation: (a) $S_{1}$ is on, $S_{2}$ is off; (b) $S_{1}$ is off, $S_{2}$ is on. 


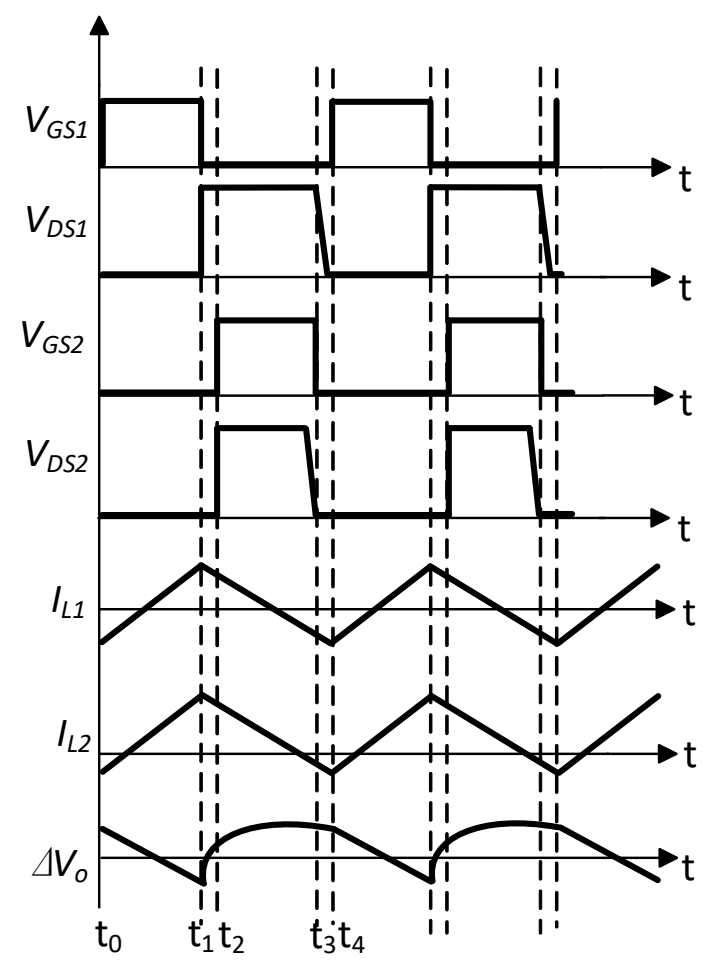

Figure 9. TCM SEPIC converter with zero voltage switching (ZVS) waveform.

As shown in Figure 10, use the SIMetrix/SIMPLIS software (developed by Portland, SIMPLIS Technologies, Inc.) to run the purposed circuit. The simulation waveform can be verified by matching theory waveform, as shown in Figure 11, the main power switch operates at zero voltage switching (ZVS).

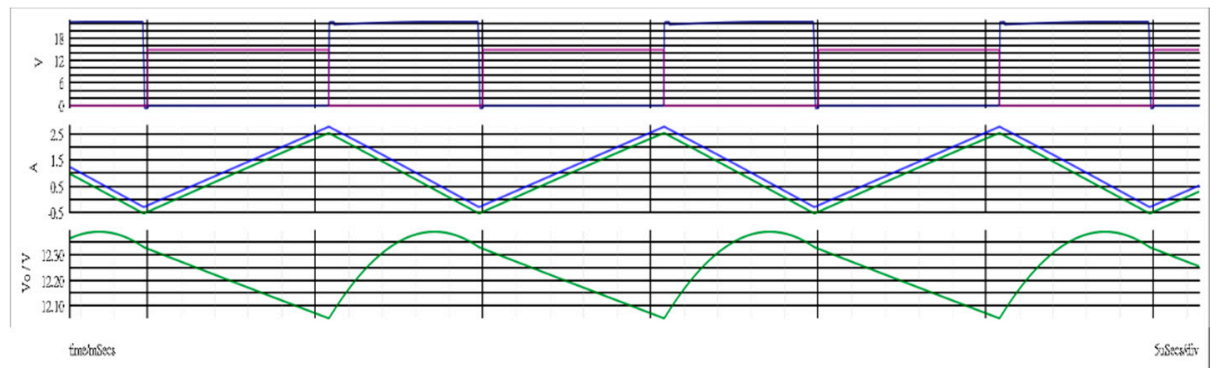

Figure 10. Simulation waveform.

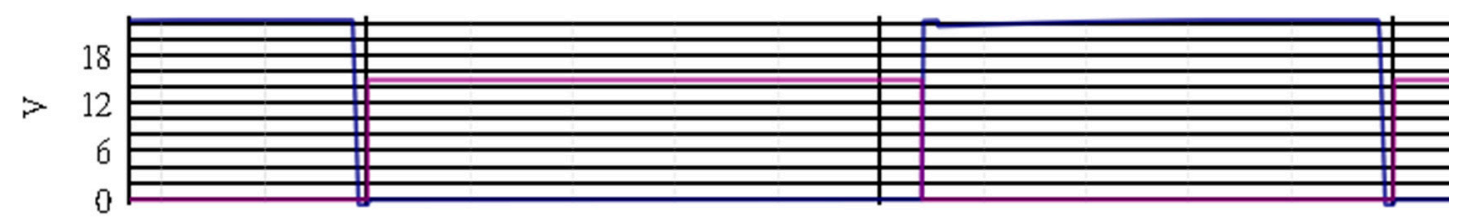

Figure 11. Power switch in ZVS (blue is $V_{D S}$ and purple is $V_{G S}$ ).

\section{Digital Control Design}

This paper proposes a single-stage SEPIC converter with ZVS to operate in TCM. The circuit control uses Texas Instruments digital development board for control. In this paper, a digital method was used for control. The input of the circuit, in this paper, is powered by analog solar energy; thus, it stores energy in the battery during the day and can also supply energy to the OLED of the load. It can be used if indoor lighting is needed during the day. To prevent the maximum power of the load from being used and to prevent the battery from being affected by natural environmental factors, such as 
the sun being temporarily shaded by clouds or weak sunlight, adding maximum power point tracking (MPPT) is necessary to maintain the maximum power supply of the load end and the battery.

Disturbance observation method (perturb-and-observe method, $\mathrm{P} \& \mathrm{O}$ ) is the most commonly used approach for maximum power tracking. In this paper, this control method is also used. Disturbance observation method is used to periodically increase or decrease the size of the load to change the battery terminal voltage and output power. The voltage and power of the load change are compared to determine whether to increase or decrease them to reach the maximum power point. The disadvantage of this method is that when the maximum power point is reached, the disturbance will not stop because of it, but will shake around the maximum power point, thereby causing energy loss and reducing efficiency. As shown in Figure 12, the maximum power point is clear, and it will continue to increase or decrease and change the cycle of the switch, thereby, prompting the power to find the maximum point to achieve maximum power tracking.

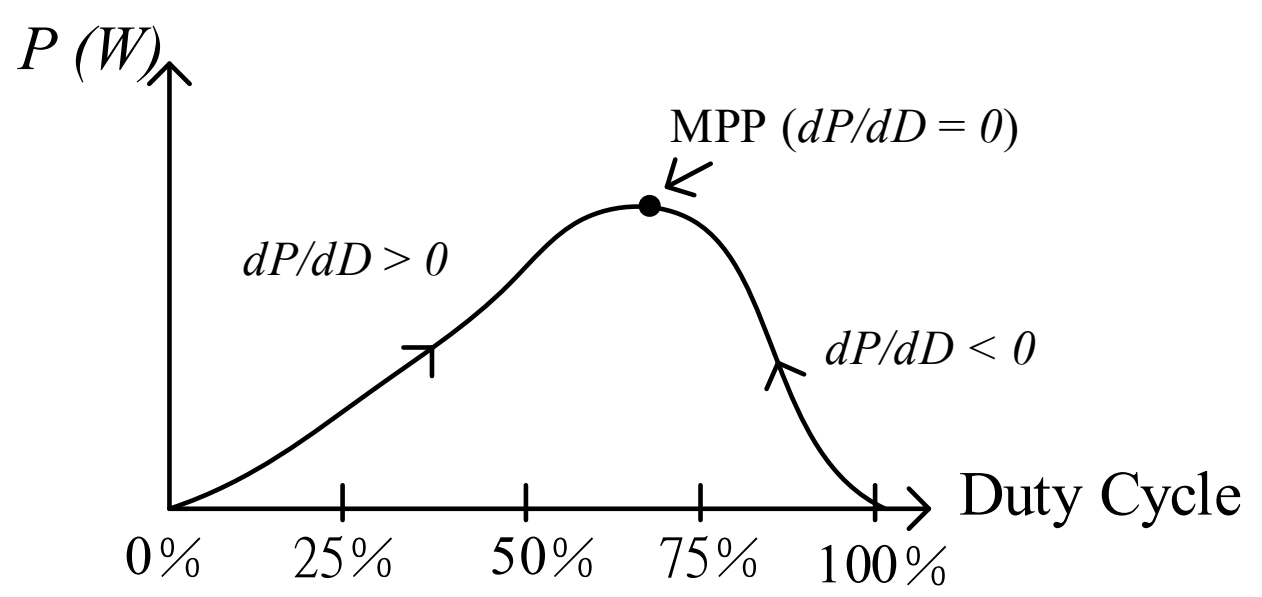

Figure 12. Perturb-and-observe method.

\section{Circuit Design Simulation and Measured Results}

In this paper, the circuit specifications are set first. Then, the component parameters are calculated according to the circuit calculation formula. Afterward, the SEPIC circuit simulation with zero voltage switching uses the SIMetrix/SIMPLIS software (developed by Portland, SIMPLIS Technologies, Inc.) for circuit simulation to simulate the feasibility of improving the proposed original circuit architecture.

The circuit specifications and component specifications of this paper are shown in Tables 1 and 2.

Table 1. Circuit specifications.

\begin{tabular}{cc}
\hline Item & Value \\
\hline Input voltage & $10-40 \mathrm{~V}$ \\
\hline Output voltage & $12 \mathrm{~V} / 1 \mathrm{~A}$ \\
\hline Switching frequency & $100 \mathrm{kHz}$ \\
\hline Frequency Conversion & $70-100 \mathrm{kHz}$ \\
\hline
\end{tabular}

Table 2. Circuit component specification.

\begin{tabular}{cc}
\hline Component & Specification \\
\hline MOSFET & IRF $2907 Z\left(V_{D S}=75 \mathrm{~V}, R_{D S(o n)}=4.5 \mathrm{~m} \Omega\right)$ \\
\hline Current Sensor & $\mathrm{HX}-10 \mathrm{P}$ \\
\hline Inductors & $18 \mu \mathrm{H}$ \\
\hline Gate driver & $\mathrm{HCPL}-3120$ \\
\hline
\end{tabular}


Figures 13-16 show the same switching frequency of $100 \mathrm{kHz}$ and different input voltages of 10 , 18,30 , and $40 \mathrm{~V}$. The first waveform is the gate and drain sources of the main power switch from the simulation. The simulation shows the interval $t_{3}-t_{4}$ that the $V_{D S 1}$ of the first main power switch drops to zero, and $V_{G S 1}$ is turned on, with the action of zero-voltage switching. The second waveform is the current waveform of the two inductors, and the current waveforms of the two inductors are the same phase. Both inductor currents fall below the zero level to the negative region until the main power switch is turned on, and then rise. The third waveform is the output voltage. When the input voltage is different, and the main switch has zero voltage switching, the output can be stabilized at 12 V. It can be verified by simulation to match the theoretical waveform.

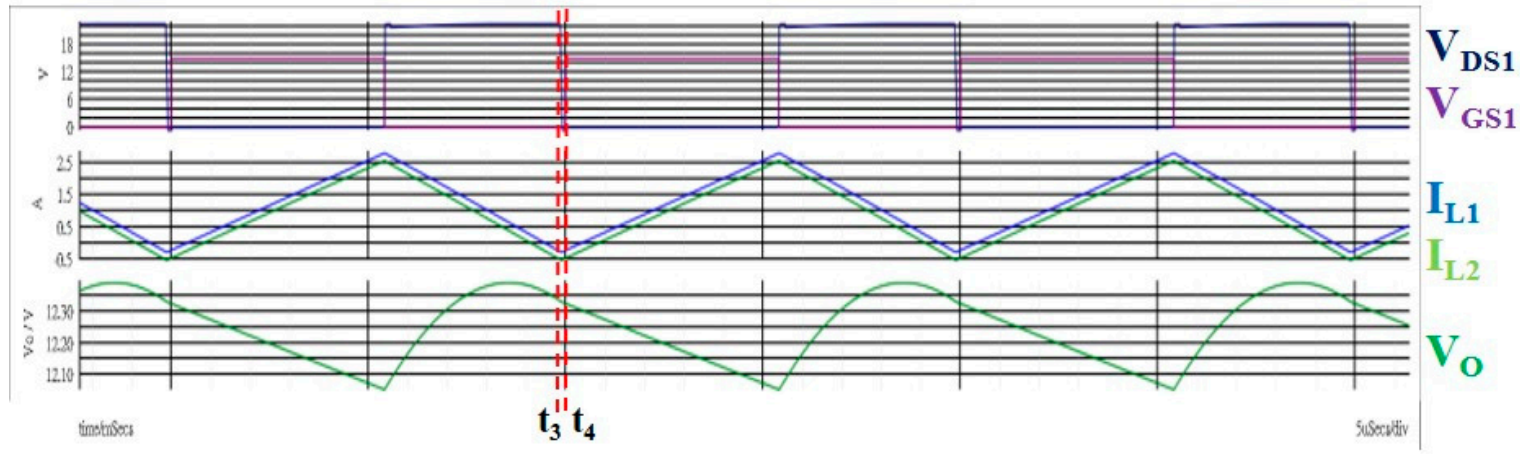

Figure 13. $V_{G S 1}, V_{D S 1}, I_{L 1}, I_{L 2}, V_{0}$ of input $10 \mathrm{~V}$.

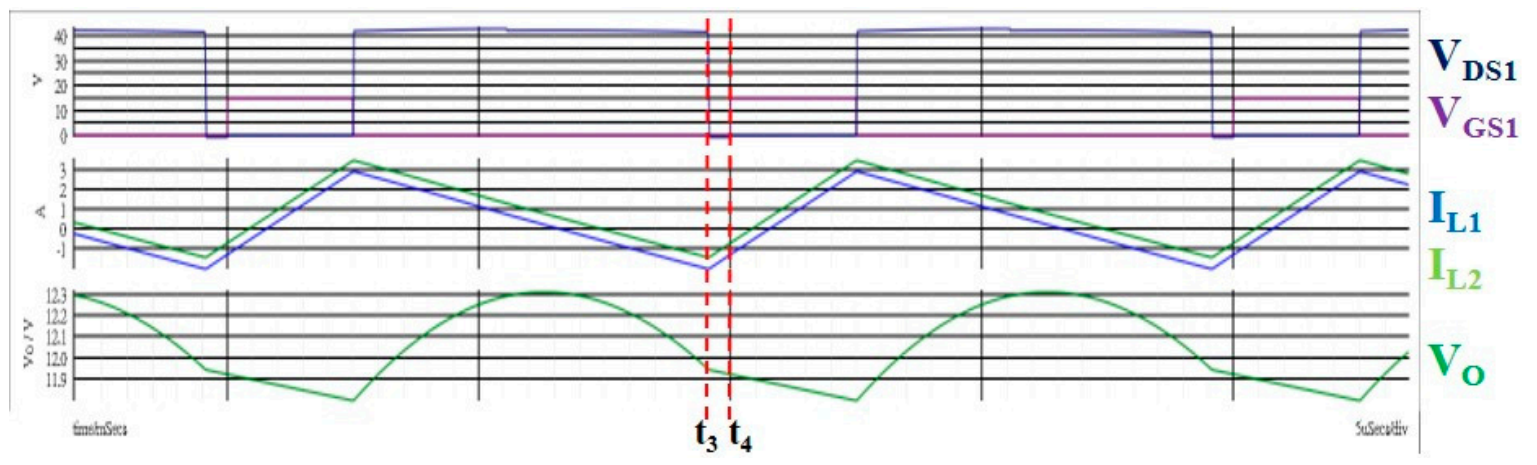

Figure 14. $V_{G S 1}, V_{D S 1}, I_{L 1}, I_{L 2}, V_{0}$ of input $18 \mathrm{~V}$.

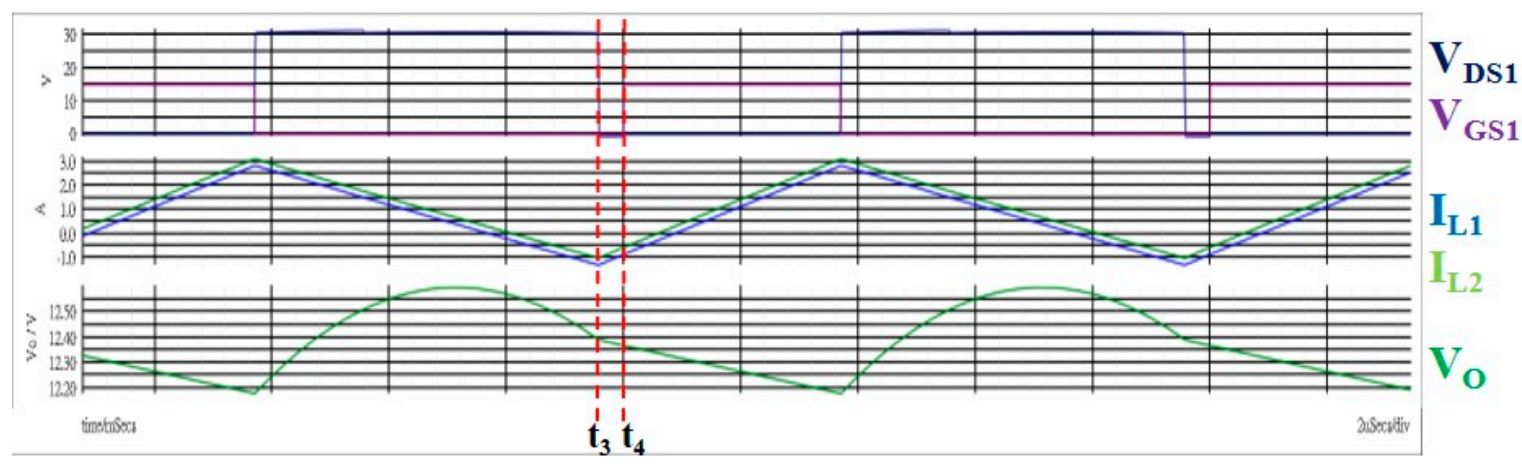

Figure 15. $V_{G S 1}, V_{D S 1}, I_{L 1}, I_{L 2}, V_{0}$ of input $30 \mathrm{~V}$. 


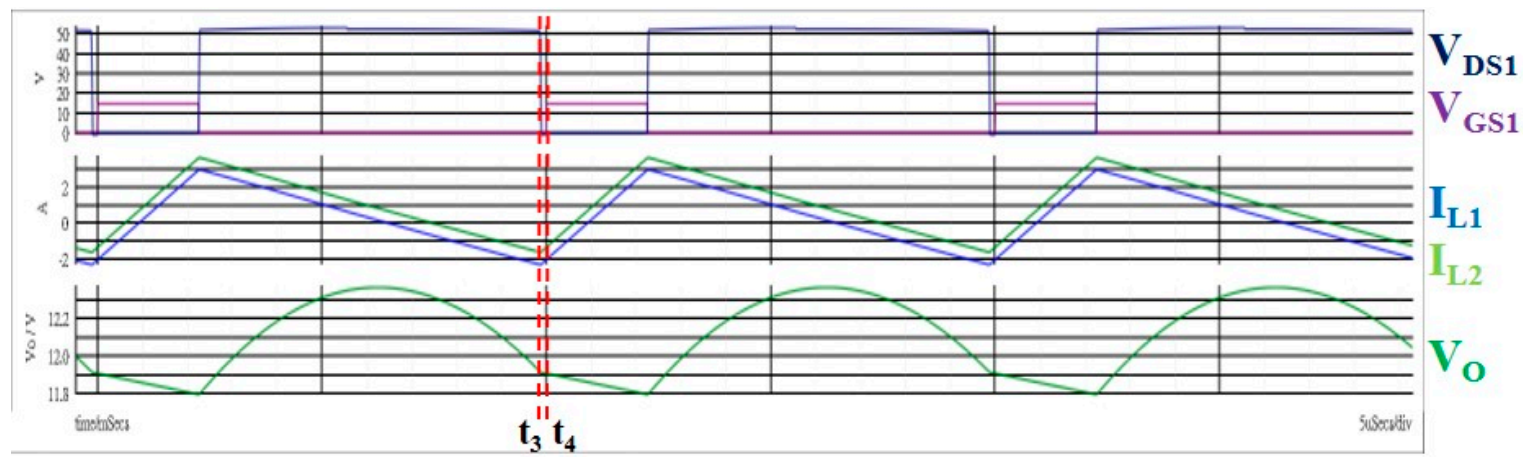

Figure 16. $V_{G S 1}, V_{D S 1}, I_{L 1}, I_{L 2}, V_{0}$ of input $40 \mathrm{~V}$.

\section{Measured Waveform}

The SEPIC circuit with zero voltage switching, mentioned in this paper, uses a high-voltage DC power supply for input signal stability and low noise. The two driver ICs use a small power supply GPD3060D, and the load is simulated using a Chroma load machine. The output terminal is connected to the OLED, and a differential isolation carbon rod is used to side the waveform of the power switch. The current waveform uses a current probe that can measure $30 \mathrm{~A}$.

Measurement of the SEPIC circuit with zero voltage switching is adopted. The switching signal uses a digital control method. The circuit uses two power switches. Thus, to prevent the two power switches from malfunctioning and causing component damage, a dead-time mechanism is added to the control aspect to ensure that the $V_{G S}$ of the two power switches are staggered when they are turned on and that the $V_{G S}$ of the second power switch is delayed for some time before turning on. The duty cycle of the two power switches is at a complementary mode. The measured waveforms are shown in Figures 17 and 18. The input voltages are $10 \mathrm{~V}$ and $40 \mathrm{~V}$. The duty cycle of the two power switches is at a complementary mode. The switching frequency is $70 \mathrm{kHz}$; thus, it outputs two power switch waveforms and inductor current waveforms with a fixed $12 \mathrm{~V}$ current of $1 \mathrm{~A}$. As shown in Figures 19-21, the input voltages are $10 \mathrm{~V}$ and $40 \mathrm{~V}$, the duty cycle of the two power switches is at a complementary mode, and the switching frequency is $100 \mathrm{kHz}$. Thus, it outputs two power switches with a fixed $12 \mathrm{~V}$ current $1 \mathrm{~A}$. The waveform and the inductor current waveform can be verified for consistency with the theoretical waveform by measuring the waveform at different input voltages and switching frequencies. The measured waveforms, simulated waveforms, and theoretical waveforms are consistent and verify feasibility.

From the measured data in Table 3 and calculated by the efficiency formula, the efficiency curve shown in Figure 22, the proposed converter efficiency curve is measured with different input voltages of $10 \mathrm{~V}, 18 \mathrm{~V}, 30 \mathrm{~V}$, and $40 \mathrm{~V}$, fixed voltage, and current of output. When the input is $18 \mathrm{~V}$ and the output is $12 \mathrm{~V} / 1 \mathrm{~A} / 12 \mathrm{~W}$, the efficiency is up to $96.3 \%$. 


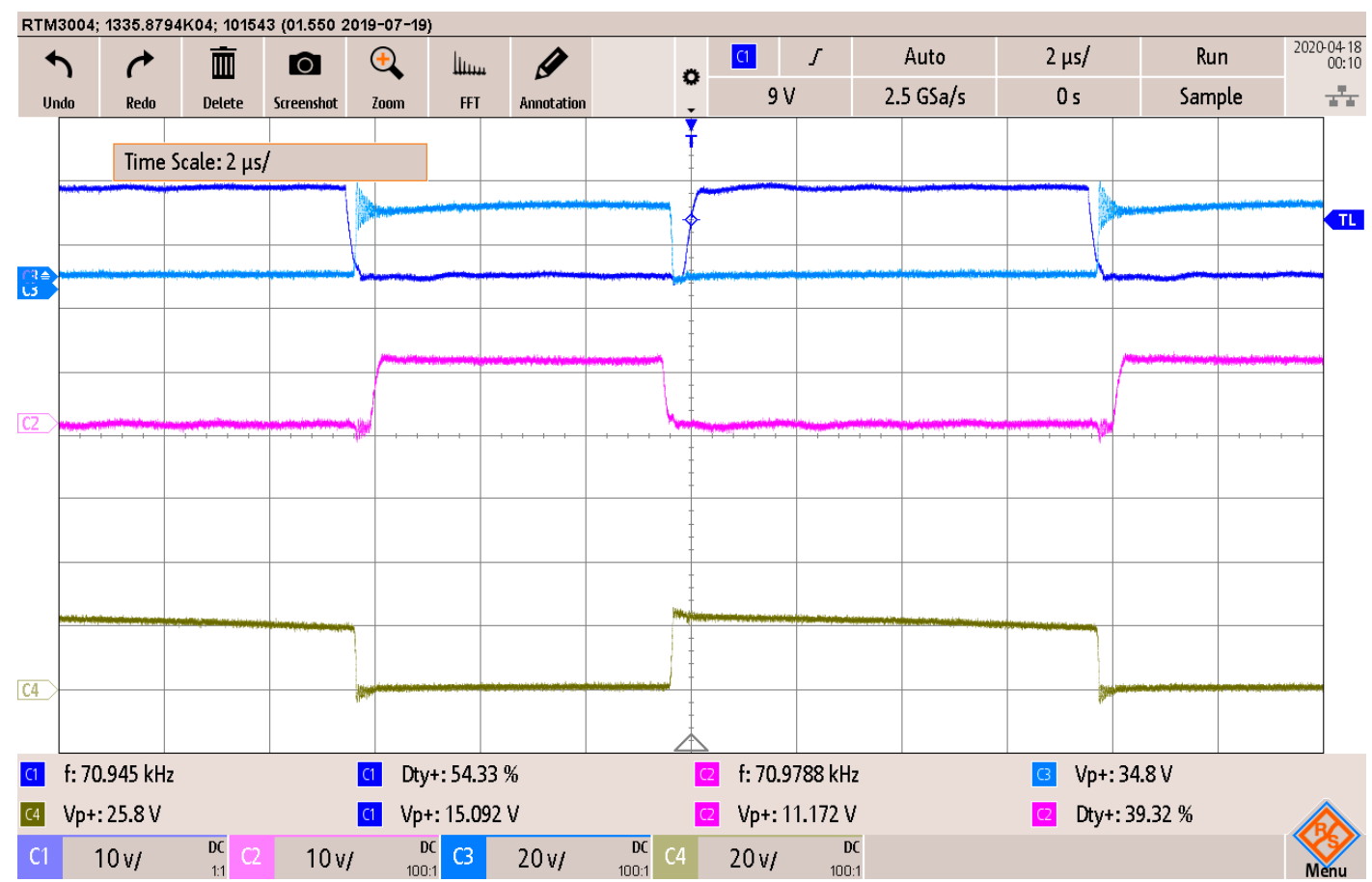

Figure 17. Waveforms of switch $V_{G S}$ and $V_{D S}$ with $10 \mathrm{~V}$ of input and $12 \mathrm{~V} / 1 \mathrm{~A}$ of output (CH1, $V_{G S 1}$; $\left.\mathrm{CH} 2, V_{G S 2} ; \mathrm{CH} 3, V_{D S 1} ; \mathrm{CH} 4, V_{D S 2}\right)$.

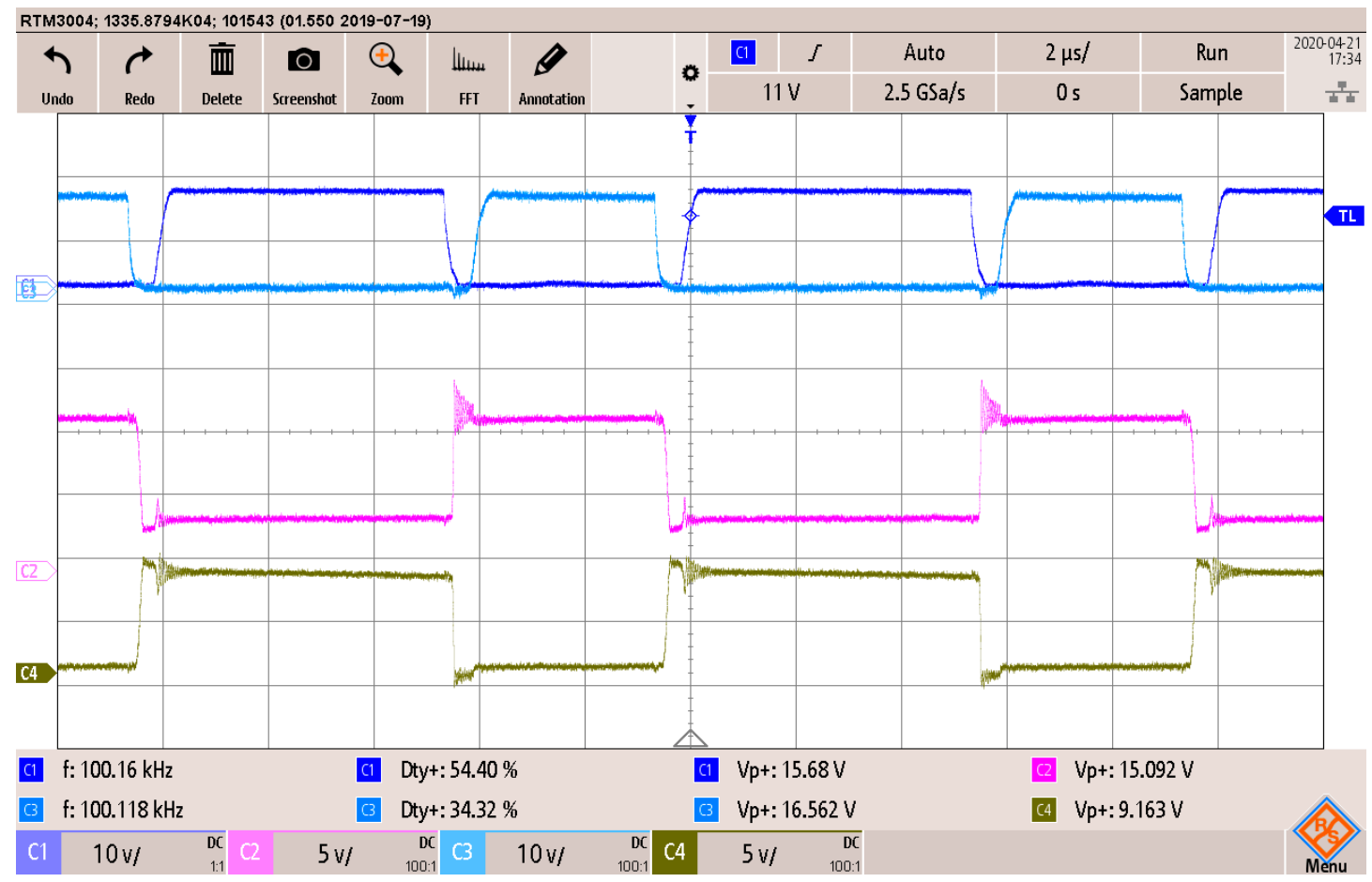

Figure 18. Waveforms of switch $V_{G S}, V_{D S}$ and inductor current with input $10 \mathrm{~V}$, output $12 \mathrm{~V} / 1 \mathrm{~A}(\mathrm{CH} 1$, $\left.I_{L} ; \mathrm{CH} 2, V_{G S 1} ; \mathrm{CH} 3, V_{D S 1} ; \mathrm{CH} 4, V_{D S 2}\right)$. 


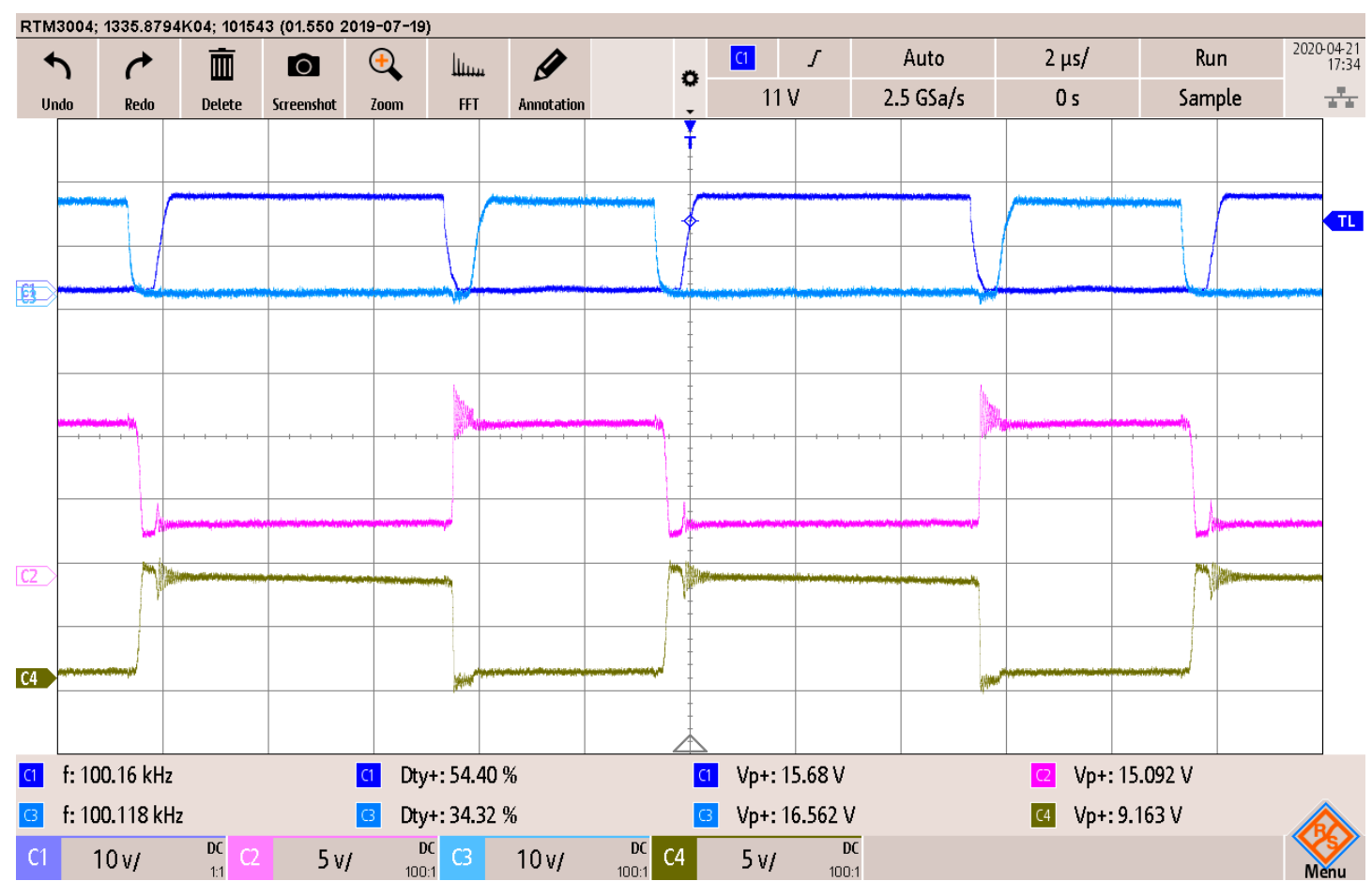

Figure 19. Waveforms of switch $V_{G S}$ and $V_{D S}$ with $10 \mathrm{~V}$ of input and $12 \mathrm{~V} / 1$ A of output $\left(\mathrm{CH} 1, V_{G S 1}\right.$; $\left.\mathrm{CH} 2, V_{D S 1} ; \mathrm{CH} 3, V_{G S 2} ; \mathrm{CH} 4, V_{D S 2}\right)$.

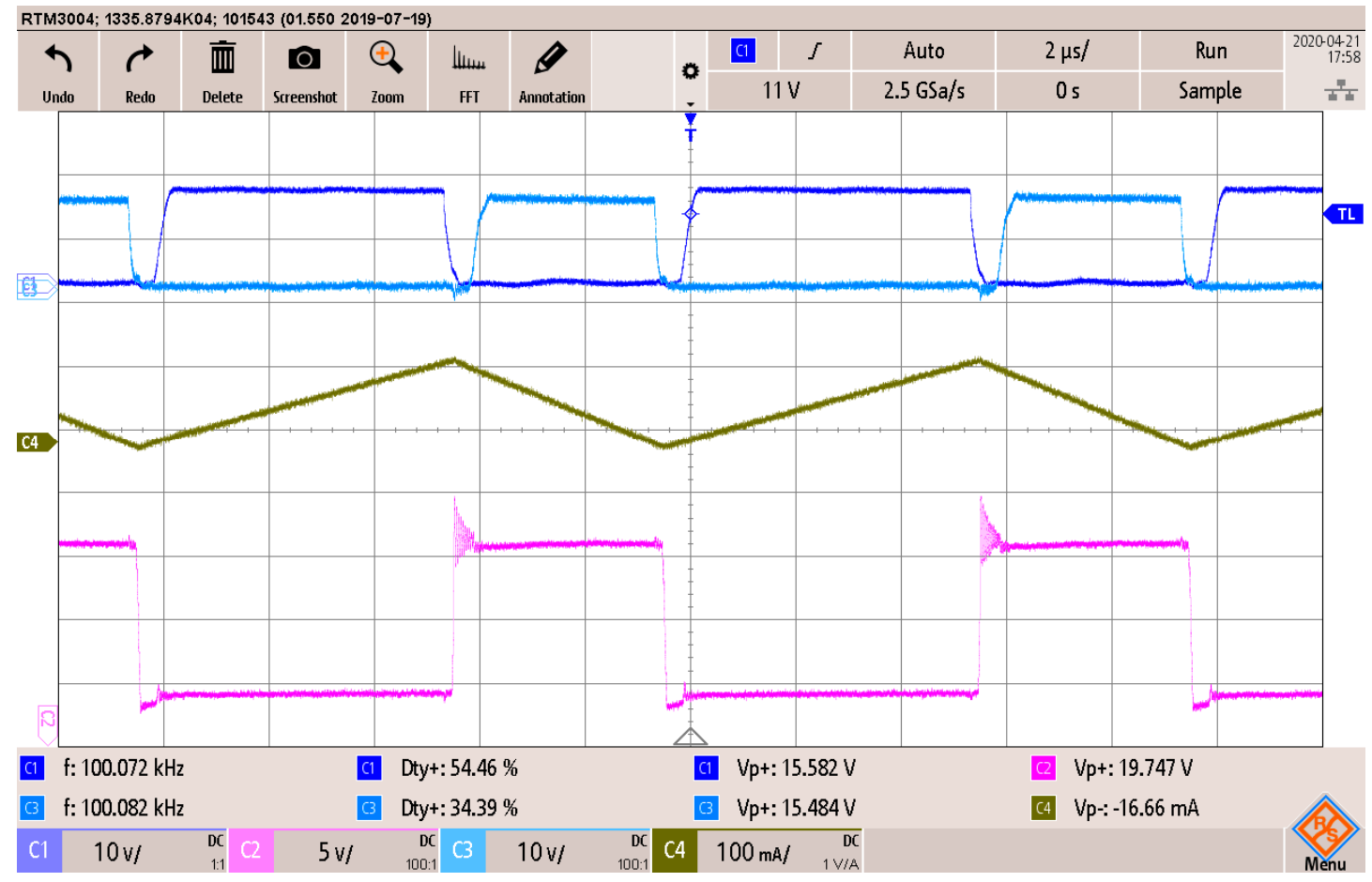

Figure 20. Waveforms of switch $V_{G S}, V_{D S}$ and inductor current with $10 \mathrm{~V}$ of input and $12 \mathrm{~V} / 1 \mathrm{~A}$ of output $\left(\mathrm{CH} 1, V_{G S 1} ; \mathrm{CH} 2, V_{D S 1} ; \mathrm{CH} 3, V_{G S 1} ; \mathrm{CH} 4, I_{L}\right)$. 


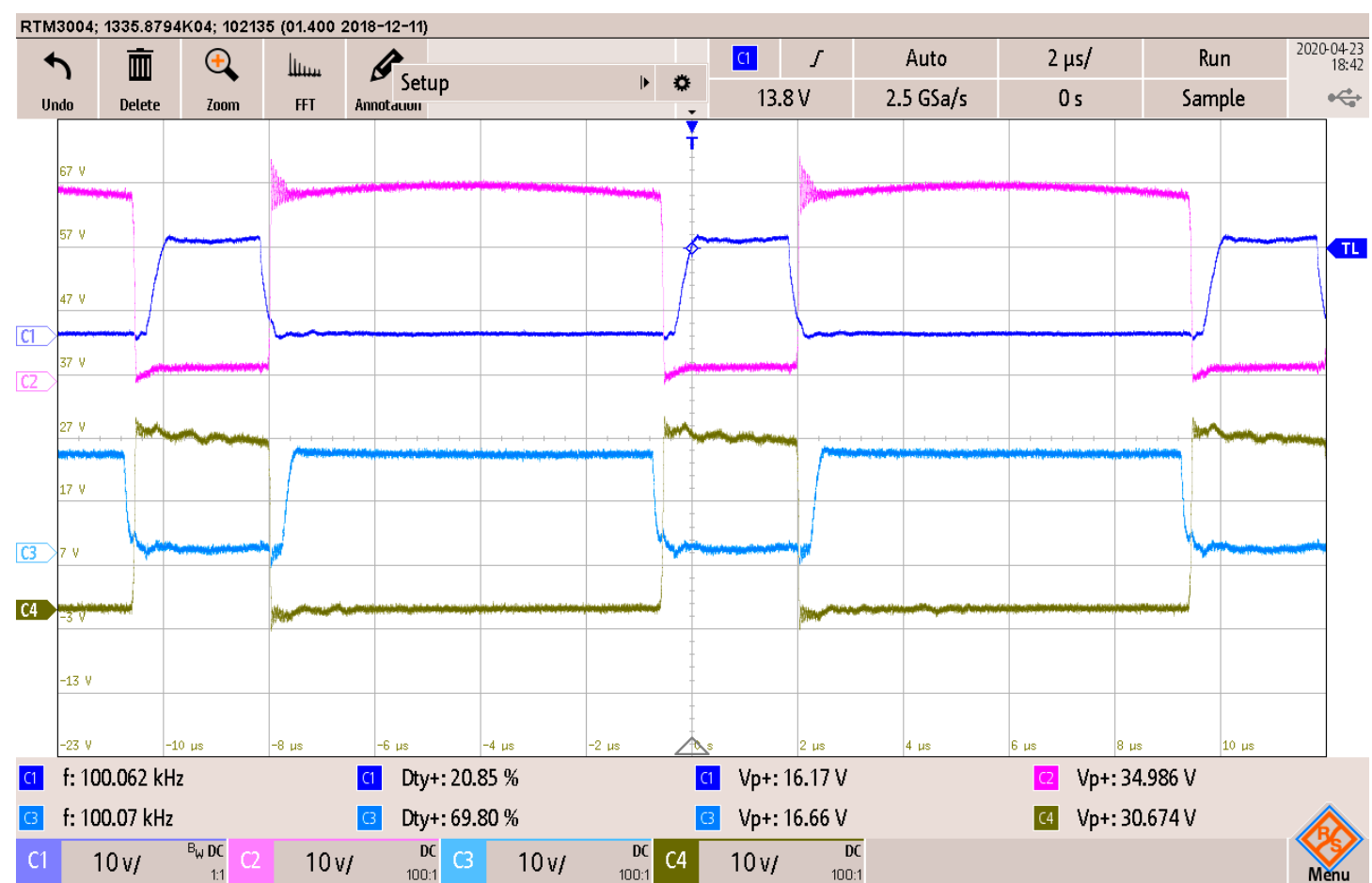

Figure 21. Waveforms of switch $V_{G S}$ and $V_{D S}$ with input of $40 \mathrm{~V}$ and output of $12 \mathrm{~V} / 1 \mathrm{~A}$. (CH1, $V_{G S 1}$; $\left.\mathrm{CH} 2, V_{D S 1} ; \mathrm{CH} 3, V_{G S 2} ; \mathrm{CH} 4, V_{D S 2}\right)$.

Table 3. Measured data of circuit.

\begin{tabular}{ccccccc}
\hline & Vin & & \multicolumn{3}{c}{ Vout } & \multirow{2}{*}{ Efficiency } \\
\cline { 1 - 5 } $\mathbf{V}$ & $\mathbf{A}$ & $\mathbf{P}$ & $\mathbf{V}$ & $\mathbf{A}$ & $\mathbf{P}$ & \\
\hline 9.9972 & 1.3795 & 13.79114 & 12.328 & 1 & 12.328 & $89.39 \%$ \\
\hline 18.003 & 0.711 & 12.80013 & 12.328 & 1 & 12.328 & $96.31 \%$ \\
\hline 30.816 & 0.4483 & 13.81481 & 12 & 1.0269 & 12.3228 & $89.20 \%$ \\
\hline 40.022 & 0.339 & 13.56746 & 12.18 & 1 & 12.18 & $89.77 \%$ \\
\hline
\end{tabular}

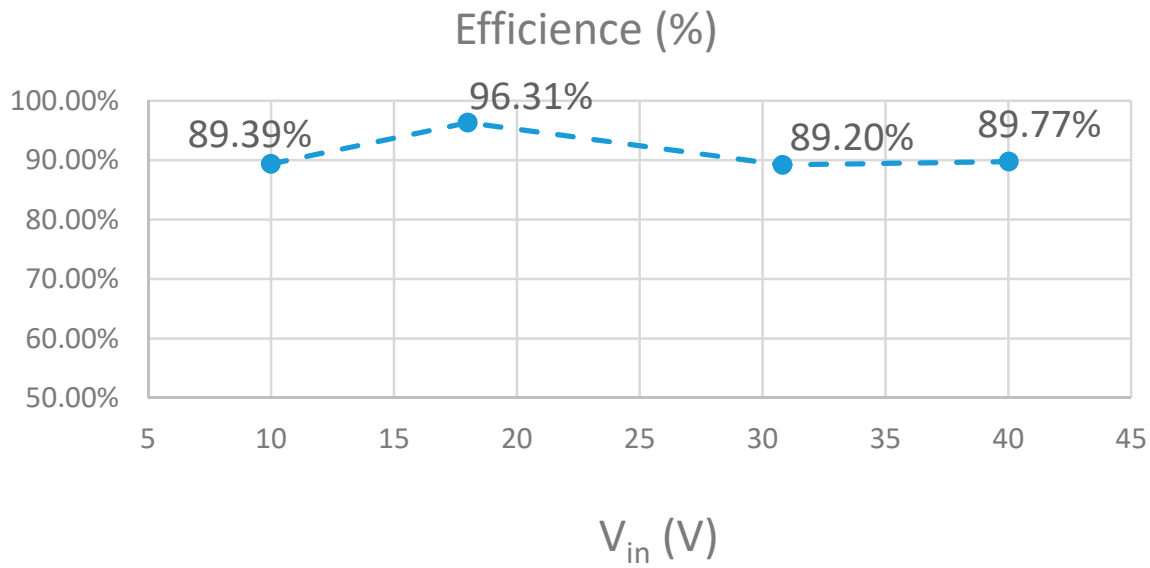

Figure 22. Efficiency performance of the proposed converter.

\section{Conclusions}

This paper proposes a single stage SEPIC converter circuit, which is applied to the OLED driver circuit. The output Schottky diode from the original SEPIC is replaced by a MOSFET. Deadtime is added to prevent the on-state overlapping of two switches, with zero voltage switching. The circuit 
operates in TCM. The digital control methods used are maximum power tracking and frequency modulation using a battery to supply the converter and illuminate the OLED at night. Finally, a prototype was implemented to show the feasibility under a DC input voltage range of 10-40 V. The DC output is $12 \mathrm{~V} / 1 \mathrm{~A} / 12 \mathrm{~W}$ with a conversion efficiency of up to $96.3 \%$.

Author Contributions: Conceptualization, Z.-R.L.; Data curation, Z.-R.L.; Formal analysis, Z.-R.L.; Funding acquisition, H.-J.C.; Investigation, Z.-R.L.; Methodology, Z.-R.L.; Project administration, Z.-R.L.; Resources, H.-J.C.; Supervision, H.-J.C.; Validation, Z.-R.L.; Visualization, Z.-R.L.; Writing-original draft, Z.-R.L.; Writing一review \& editing, H.-J.C. All authors have read and agreed to the published version of the manuscript.

Funding: This research received no external funding.

Conflicts of Interest: The authors declare no conflict of interest.

\section{References}

1. Technology Information ABC. Brief Description of the Characteristics of UIV OLED Lighting Source, Understand the Different Light. Home Furnish. 2019. Available online: https://kknews.cc/home/3v9lng3.html (accessed on 26 October 2020).

2. Xiong, S.Z.; Xie, W.L.; Zhao, Y.; Wang, J.S.; Liu, E.F.; Wu, C.Y. A Simple and Flexible driver for OLED. In Proceedings of the 5th Asian Symposium on Information Display, ASID'99, Hsinchu, Taiwan, 6 August 2002.

3. Buso, D.; Bhosle, S.; Liu, Y.; Ternisien, M.; Renaud, C.; Chen, Y.M. OLED Electrical Equivalent Device for Driver Topology Design. IEEE Trans. Ind. Appl. 2014, 50, 1459-1468. [CrossRef]

4. Jacobs, J.; Hente, D.; Waffenschmidt, E. Drivers for OLEDs. In Proceedings of the 2007 IEEE Industry Applications Annual Meeting, New Orleans, LA, USA, 23-27 September 2007.

5. Bęczkowski, S.; Munk-Nielsen, S. Led Spectral and Power Characteristics under Hybrid Pwm/Am Dimming Strategy. In Proceedings of the 2010 IEEE Energy Conversion Congress and Exposition, Atlanta, GA, USA, 1 November 2010.

6. Park, J.; Ban, T.; Choi, D. Organic LEDs Combined With Inorganic LEDs. J. Lightwave Technol. 2011, 29, 2684-2689. [CrossRef]

7. Le Minh, H.; Ghassemlooy, Z.; Burton, A.; Haigh, P.A. Equalization for organic light emitting diodes in visible light communications. In Proceedings of the 2011 IEEE GC Wkshps, Houston, TX, USA, 5-9 December 2011.

8. Han, R.; Yang, C.C.; Chen, X.; Han, X.Q.; Zhang, J.; Li, C.N. Design of an Intelligent White-OLED Lighting System using Power Line Communication. In Proceedings of the 2012 2nd International CECNet, Yichang, China, 21-23 April 2012.

9. Liu, Y.; Chen, Y.M.; Buso, D.; Zissis, G. Influence of Driving Current on Photometric Performances of a White Light OLED. IEEE Trans. Ind. Appl. 2016, 52, 5219-5225. [CrossRef]

10. Wu, Y.-L. Switching Power Supply Converter for Principle and Practical Design; Wen-Sheng Publisher: Taipei, Taiwan, 2015.

11. Falin, J. Designing DC/DC converters based on SEPIC topology. Analog Appl. J. 2018, 18-26.

12. Verma, M.; Kumar, S.S. Hardware Design of SEPIC Converter and its Analysis. In Proceedings of the International Conference on Current Trends towards Converging Technologies (ICCTCT), Coimbatore, India, 1-3 March 2018.

Publisher's Note: MDPI stays neutral with regard to jurisdictional claims in published maps and institutional affiliations.

(C) 2020 by the authors. Licensee MDPI, Basel, Switzerland. This article is an open access article distributed under the terms and conditions of the Creative Commons Attribution (CC BY) license (http://creativecommons.org/licenses/by/4.0/). 